\title{
Corrections to AASLD Guidelines on Chronic Hepatitis B
}

To the Editor:

We would appreciate if corrections to Tables 2 and 10 in Lok and McMahon (Hepatology 2007;45:507-539) and a cautionary note on the use of entecavir in patients with hepatitis B virus (HBV)/human immunodeficiency virus (HIV) coinfection not simultaneously receiving highly active antiretroviral therapy (HAART) be brought to the attention of our readers.

We deeply regret that Table 2 regarding who should be screened for HBV infection had an error: in the first bullet point, "South Asia" should be replaced with "Asia". Below is a corrected version of Table 2 .

Table 2. Groups at High Risk for HBV Infection Who Should Be Screened $^{9}$

- Individuals born in areas of high" ${ }^{\#}$ and intermediate prevalence rates ${ }^{\dagger}$ for HBV including immigrants and adopted children ${ }^{*}$

- Asia: all countries (except Sri Lanka)

- Africa: all countries

- South Pacific Islands: all countries and territories (except nonindigenous populations of New Zealand and Australia)

- Middle East: all countries (except Cyprus)

- Western Europe: Greece, Italy, Malta, Portugal, and Spain

- Eastern Europe: all countries (except Hungary)

- The Arctic: indigenous populations

- South America: Argentina, Bolivia, Brazil, Ecuador, Guyana, Suriname, Venezuela, and Amazon region of Colombia and Peru

- Central America: Belize, Guatemala, Honduras, and Panama

- Caribbean: Antigua and Barbuda, Dominica, Dominican Republic, Grenada, Haiti, Jamaica, Puerto Rico, St. Kitts and Nevis, St. Lucia, St. Vincent and Grenadines, Trinidad and Tobago, and Turks and Caicos.

- Other high-risk groups recommended for screening

- Household and sexual contacts of HBsAg-positive persons*

- Persons who have ever injected drugs*

- Persons with multiple sexual partners or history of sexually transmitted disease*

- Men who have sex with men*

- Inmates of correctional facilities*

- Individuals with chronically elevated ALT or AST*

- Individuals infected with HCV or HIV*

- Patients undergoing renal dialysis*

- All pregnant women

If HBsAg-positive persons are found in the first generation, subsequent generations should be tested

\#HBsAg prevalence $>8 \%$

†HBsAg prevalence $2 \%-7 \%$

*Those who are seronegative should receive hepatitis $B$ vaccine

Dose adjustments for telbivudine in patients with impaired renal function in Table 10 should also be revised to conform with the package insert as follows:
Table 10. Adjustment of Adult Dosage of Nucleos(t)ide Analog in Accordance with Creatinine Clearance

\begin{tabular}{ll}
\hline Creatinine clearance (ml/min) & Recommended dose \\
\hline d. Telbivudine & \\
$\geq 50$ & $600 \mathrm{mg}$ once daily \\
$30-49$ & $600 \mathrm{mg}$ once every 48 hours \\
$<30$ (not requiring dialysis) & $600 \mathrm{mg}$ once every 72 hours \\
End-stage renal disease & $600 \mathrm{mg}$ once every 96 hours* \\
\hline
\end{tabular}

*To be administered after hemodialysis

\section{Special Populations}

\section{Co-infection with $\mathrm{HBV}$ and $\mathrm{HIV}$}

We were also informed of a recent case report in which the selection of an HIV mutant containing the methionine-to-valine (M184V) substitution was found during entecavir treatment for chronic hepatitis B in an HBV/ HIV coinfected patient who was not simultaneously receiving HAART. ${ }^{1}$ In light of this report, Bristol-Myers Squibb has advised caution regarding use of entecavir in this setting. Although the data is preliminary, we agree with the recommendations in the cautionary letter sent to all health care providers. Thus, until further data are available, we have revised recommendation \#33 to read as:

33. Patients who are not on HAART and are not anticipated to require HAART in the near future should be treated with an antiviral therapy that does not target HIV, such as pegIFN- $\alpha$, adefovir, or entecavir. Caution should be exercised if entecavir is used in this setting. Although telbivudine does not target HIV, it should not be used in this circumstance. (II-3)

ANNA S. F. LOK ${ }^{1}$

BRIAN J. MCMAHON ${ }^{2}$

${ }^{1}$ Division of Gastroenterology, University of Michigan Medical Center, Ann Arbor, MI

${ }^{2}$ Liver Disease and Hepatitis Program, Alaska Native Medical Center and Arctic Investigations Program, Centers for Disease Control, Anchorage, AK

\section{Reference}

1. McMahon M, Jilek B, Brennan T, Shen L, Zhou Y, Bhat S, Hale B, Hegarty R, Silicano R, Thio C. The Anti-Hepatitis B Drug Entecavir Inhibits HIV-1 Replication and Selects HIV-1 Variants Resistant to Antiretroviral Drugs. Presented at the 14th Conference on Retroviruses and Opportunistic Infections, Los Angeles, CA, February 2007.

Copyright (C) 2007 by the American Association for the Study of Liver Diseases. Published online in Wiley InterScience (www.interscience.wiley.com). DOI 10.1002/hep. 21738

Potential conflict of interest: Nothing to report. 